\title{
Reappraisal of the relation between blood lead concentration and blood pressure among the general population in Taiwan
}

\author{
Nain-Feng Chu, Saou-Hsin Liou, Trong-Neng Wu, Po-Ya Chang
}

Departments of Public Health and Internal Medicine, Tri-Service General Hospital, National Defense Medical Center, Taipei, Taiwan, Republic of China N-F Chu S-H Liou

Department of Health, The Executive Yuan, Taipei, Taiwan, Republic of China T-N Wu

P-Y Chang

Correspondence to: Dr Nain-Feng Chu, Department of Public Health, National Defense Medical Center, Taipei, Taiwan, Republic of China. Telephone 008862 23670210; email: chuepi@ ndmci.ndmctsgh.edu.tw

Accepted 17 September 1998

\begin{abstract}
Objectives-The relation between blood lead concentration $(\mathrm{PbB})$ and blood pressure was examined in a Taiwan nationwide population survey of PbB from July 1993 to June 1994.

Methods-After multistage sampling procedures, 2800 subjects (1471 males and 1329 females) with a mean (range) age of 44 (15-85) years were enrolled in this study. Anthropometric, blood pressure, and lifestyle factors were measured during household visits. The $\mathrm{PbB}$ was measured with a flameless atomic absorption spectrophotometer and all specimens were analysed in triplicate.

Results-The mean (range) PbB among all study subjects was $6.5(0.1-69.1) \mu \mathrm{g} / \mathrm{dl}$; among males it was $7.3(0.1-69.1) \mu \mathrm{g} / \mathrm{dl}$ and among females $5.7(0.1-40.1) \mu \mathrm{g} / \mathrm{dl})$. The mean (range) systolic blood pressure among all subjects was $123(80-210) \mathrm{mm}$ Hg, among males it was $127(80-200) \mathrm{mm}$ $\mathrm{Hg}$ and among females 119 (80-210) $\mathrm{mm}$ Hg. The diastolic blood pressure among all subjects was $78(40-150) \mathrm{mm} \mathrm{Hg}$; among males it was $80(40-130) \mathrm{mm} \mathrm{Hg}$; and among females 75 (40-150) $\mathrm{mm} \mathrm{Hg}$. Age, body height, body weight, and body mass index (BMI) were significantly correlated with systolic blood pressure or diastolic blood pressure in both sexes. The $\mathrm{PbB}$ (or the natural logarithmic transformed $\mathrm{PbB}$ ) was not significantly correlated with blood pressure among males or females. After adjustment for the potential confounders of age, age ${ }^{2}$, BMI, milk intake, alcohol consumption, and cigarette smoking, systolic blood pressure was significantly associated with $\mathrm{PbB}$ among males with a regression coefficient $(\beta)$ of $0.185(p=0.015)$. No significant association between $\mathrm{PbB}$ and blood pressure was found among females.

Conclusions-From this study, only a weak association between systolic blood pressure and $\mathrm{PbB}$ was found among males. There was no strong evidence that $\mathrm{PbB}$ was a good predictor of blood pressure. However, the possiblity that long term high body lead burden could cause high blood pressure could not be ruled out on the basis of this survey.

(Occup Environ Med 1999;56:30-33)
\end{abstract}

Keywords: blood lead, blood pressure, general population
Lead is a dense silvery metal that can be easily cast, moulded, and extruded. It is often used to make sheeting and pipes, and its compounds are often used in the chemical industry. Environmental and occupational lead pollution is a common concern in developing and industrial countries and it is a worldwide public health problem. It has become an important issue for environmental health and occupational medicine in these countries.

Lead intoxication is involved with multiple systems, and causes neuropsychological effects, atherosclerotic disorders, metabolic bone effects, reproductive effects, nephrotoxicity, and carcinogenesis. ${ }^{12}$ Several studies have shown that increased blood lead concentration $(\mathrm{PbB})$ is associated with an increase in blood pressure. After adjusting for age, body mass index (BMI), and nutritional factors, $\mathrm{PbB}$ still correlated well with blood pressure. ${ }^{34}$ A metaanalysis showed that blood pressure can be decreased by $1.25 \mathrm{~mm} \mathrm{Hg}$ after the $\mathrm{PbB}$ is reduced from $10 \mu \mathrm{g} / \mathrm{dl}$ to $5 \mu \mathrm{g} / \mathrm{dl} .^{3}$ The diastolic blood pressure was significantly associated with $\mathrm{PbB}$ among females and there was a significant association between changes in $\mathrm{PbB}$ and changes in systolic blood pressure in males. There was a positive association between mortality from coronary heart disease and $\mathrm{PbB}$ and the mortality from hypertension and cerebrovascular disease among workers exposed to lead was higher than that in the general population. ${ }^{56}$ Workers exposed to low concentrations of lead had higher mortality from cerebrovascular disease than controls; however, this trend has declined and become insignificant in recent years. ${ }^{5}$ Other studies have shown that there was no consistent association between mortality from cardiovascular disease and exposure to lead at work and, after controlling for other potential confounders, the association between $\mathrm{PbB}$ and mortality from cardiovascular disease was weak and non-significant. ${ }^{8-10}$ Hense there is controversy between studies on exposure to lead and cardiovascular indices.

The purpose of this study was to evaluate the relation between $\mathrm{PbB}$ and blood pressure among the general population in Taiwan.

\section{Material and methods}

STUDY DESIGN AND SAMPLING

We conducted a multicentre cross sectional nationwide $\mathrm{PbB}$ survey from July 1993 to June 1994 in Taiwan. This survey was conducted by visiting households. People who were older than 15 years and had been registered as living 
Table 1 General characteristics of study subjects of different sexes

\begin{tabular}{|c|c|c|c|c|}
\hline Variables & Mean & $S D$ & Minimum & Maximum \\
\hline \multicolumn{5}{|l|}{ Total $(n=2800)$} \\
\hline Age $(y)$ & 44.3 & 15.4 & 15.0 & 85.0 \\
\hline Body weight $(\mathrm{kg})$ & 61.6 & 10.7 & 36.0 & 105.0 \\
\hline Body height $(\mathrm{cm})$ & 161.6 & 7.9 & 132.0 & 192.0 \\
\hline Body mass index $\left(\mathrm{kg} / \mathrm{m}^{3}\right)$ & 23.6 & 3.5 & 15.2 & 39.4 \\
\hline $\mathrm{SBP}(\mathrm{mm} \mathrm{Hg})$ & 123.2 & 18.0 & 80.0 & 210.0 \\
\hline $\mathrm{DBP}(\mathrm{mm} \mathrm{Hg})$ & 77.8 & 11.4 & 40.0 & 150.0 \\
\hline Blood lead $(\mu \mathrm{g} / \mathrm{dl})$ & 6.5 & 4.7 & 0.1 & 69.1 \\
\hline \multicolumn{5}{|l|}{ Male $(\mathrm{n}=1471)$} \\
\hline Age $(y)$ & 45.6 & 15.9 & 15.0 & 85.0 \\
\hline Body weight $(\mathrm{kg})$ & 66.2 & 10.2 & 40.0 & 105.0 \\
\hline Body height $(\mathrm{cm})$ & 166.7 & 6.1 & 137.0 & 192.0 \\
\hline Body mass index $\left(\mathrm{kg} / \mathrm{m}^{3}\right)$ & 23.8 & 3.3 & 15.5 & 39.4 \\
\hline $\mathrm{SBP}(\mathrm{mm} \mathrm{Hg})$ & 126.7 & 17.2 & 80.0 & 200.0 \\
\hline $\mathrm{DBP}(\mathrm{mm} \mathrm{Hg})$ & 80.0 & 11.2 & 40.0 & 130.0 \\
\hline Blood lead $(\mu \mathrm{g} / \mathrm{dl})$ & 7.3 & 5.2 & 0.1 & 69.1 \\
\hline \multicolumn{5}{|l|}{ Female $(n=1329)$} \\
\hline Age (y) & 42.7 & 14.7 & 15 & 84 \\
\hline Body weight $(\mathrm{kg})$ & 56.6 & 8.8 & 36.0 & 100.0 \\
\hline Body height $(\mathrm{cm})$ & 155.9 & 5.4 & 132.0 & 176.0 \\
\hline Body mass index $\left(\mathrm{kg} / \mathrm{m}^{3}\right)$ & 23.3 & 3.5 & 15.2 & 38.1 \\
\hline $\mathrm{SBP}(\mathrm{mm} \mathrm{Hg})$ & 119.4 & 18.1 & 80.0 & 210.0 \\
\hline $\mathrm{DBP}(\mathrm{mm} \mathrm{Hg})$ & 75.4 & 11.2 & 40.0 & 150.0 \\
\hline Blood lead $(\mu \mathrm{g} / \mathrm{dl})$ & 5.7 & 3.9 & 0.1 & 40.1 \\
\hline
\end{tabular}

$\mathrm{SBP}=$ systolic blood pressure; $\mathrm{DBP}=$ diastolic blood pressure.

in Taiwan for $>6$ months were the eligible study population. The researchers (who had received training for this survey) visited every household that was sampled, and before the visit a postal notice and telephone call were given to ensure that the study participants would be present during the visit. ${ }^{11}$

After multistage procedures with sampling proportional to the population, we selected the study subjects according to the urbanisation level and the size of villages of Taiwan in 1994. We first sampled the villages. In Taiwan, there were 21.13 million people living in 367 villages in 1994. According to the level of urbanisation and industrialisation, these villages were classified into 24 strata; we randomly selected 82 villages proportional to the urbanisation levels. Secondly, we sampled the study households. The numbers of households sampled from the selected village were proportional to the population size of each village. In total, we sampled 2919 households. Finally, we randomly sampled one person from each selected household to become the study population. A replacement was permitted if the sampled subject refused or failed to respond, another member or volunteer of the same household or the next neighbourhood was substituted. There was no significant difference in general characteristics

Table 2 Pearson's correlation coefficients between study variables of both sexes

\begin{tabular}{|c|c|c|c|c|c|c|c|}
\hline & $B W$ & $H T$ & $B M I$ & $S B P$ & $D B P$ & Lead & $\log P b$ \\
\hline \multicolumn{8}{|c|}{ Male $(n=1471)$ : } \\
\hline Age & -0.045 & -0.298 & 0.103 & 0.417 & 0.242 & 0.007 & -0.022 \\
\hline $\mathrm{BW}$ & & 0.419 & 0.872 & 0.186 & 0.217 & -0.009 & -0.002 \\
\hline HT & & & -0.072 & -0.081 & -0.015 & -0.033 & -0.017 \\
\hline BMI & & & & 0.248 & 0.247 & 0.008 & 0.007 \\
\hline SBP & & & & & 0.670 & 0.049 & 0.035 \\
\hline DBP & & & & & & 0.037 & 0.028 \\
\hline Lead & & & & & & & 0.824 \\
\hline \multicolumn{8}{|c|}{ Female $(n=1329)$ : } \\
\hline Age & 0.182 & -0.301 & 0.318 & 0.492 & 0.331 & 0.051 & 0.013 \\
\hline $\mathrm{BW}$ & & 0.267 & 0.898 & 0.257 & 0.270 & 0.024 & 0.014 \\
\hline $\mathrm{HT}$ & & & -0.179 & -0.094 & -0.074 & -0.048 & -0.055 \\
\hline BMI & & & & 0.302 & 0.310 & 0.048 & 0.040 \\
\hline SBP & & & & & 0.741 & 0.018 & -0.001 \\
\hline DBP & & & & & & -0.006 & -0.016 \\
\hline Lead & & & & & & & 0.816 \\
\hline
\end{tabular}

$\mathrm{BW}=$ body weight; $\mathrm{HT}=$ body height; $\mathrm{BMI}=$ body mass index; $\mathrm{SBP}=$ systolic blood pressure; $\mathrm{DBP}=$ diastolic blood pressure; $\log \mathrm{Pb}=\log$ arithmic transformed blood lead concentration. or $\mathrm{PbB}$ between the 1503 people originally sampled and the replacement population in this survey. ${ }^{11}$

\section{DATA COLLECTION}

General information

General demographic information and lifestyle characteristics (including dietary pattern, cigarette smoking, and alcohol intake) were obtained with a structured questionnaire during the household visit.

\section{Anthropometric measurements}

Body weight was measured with a standard beam balance scale with the subjects standing barefoot and wearing light indoor clothing. Weight was recorded to the nearest $0.1 \mathrm{~kg}$. Height was measured with a ruler attached to a scale and was recorded to the nearest $0.5 \mathrm{~cm}$. We calculated BMI as the ratio of body weight to body height ${ }^{2}$, and expressed it as $\mathrm{kg} / \mathrm{m}^{2}{ }^{12}$

\section{Blood pressure measurements}

After the subjects had rested for 15 minutes, in the sitting position, blood pressure was measured in the right arm with a standard mercury sphygmomanometer. The pressures at the first and fifth phase Korotkoff sounds were recorded as systolic and diastolic blood pressure. A second blood pressure reading was taken after a 5 minute rest interval. The average of these two measurements was used in the analyses.

\section{Blood lead measurements}

Venous whole blood specimens were collected in a lead free heparinised vacutainer. The blood samples were stored at $4^{\circ} \mathrm{C}$ until the analyses (2 weeks at most). The $\mathrm{PbB}$ was measured by flameless atomic absorption spectrophotometer connected to a data processor. All specimens were analysed in triplicate, and the mean was taken (SD <7\%). External and internal quality controls were applied to each series of analysis. ${ }^{11}$ The proficiency and accuracy tests showed that the measurements were within the acceptable criteria proposed by the Quebec Center for Toxicology Inter-laboratory Comparison programme Canada, and the United States Centres for Disease Control and Prevention, and the variations of measurements between laboratories were $<2 \mu \mathrm{g} / \mathrm{dl}^{11}{ }^{13}$

\section{STATISTICAL METHODS}

Data are expressed as the mean (SD) $\mathrm{PbB}$ after natural logarithmic transformation for an approximation of normal distribution. All analyses were stratified by sex to avoid any potential difference of $\mathrm{PbB}$ and blood pressure due to sex.

We calculated Pearson's correlation coefficients to evaluate the relation between the study variables and $\mathrm{PbB}$ with sex specification. Multiple regression analyses were used to evaluate the association between blood pressure and $\mathrm{PbB}$ after controlling for other potential confounders. ${ }^{14}{ }^{15}$ After univariate analyses, any variables with a $p$ value $<0.1$ were selected as candidates for the multivariate analysis model as were all variables of known biological 
Table 3 Regression analysis of blood lead and systolic blood pressure before and after adjusting for potential confounders in different sexes

\begin{tabular}{|c|c|c|c|c|}
\hline $\begin{array}{l}\text { Independent } \\
\text { variables }\end{array}$ & $\begin{array}{l}\text { Regression } \\
\text { coefficient }(\beta)\end{array}$ & $\begin{array}{l}\text { Standard } \\
\text { error of } \beta\end{array}$ & $p$ Value & $R^{2}$ \\
\hline \multicolumn{5}{|l|}{ Male $(n=1471)$ : } \\
\hline $\mathrm{Age}^{\star}$ & 0.450 & 0.026 & $<0.001$ & 0.174 \\
\hline Body mass index & 1.270 & 0.130 & $<0.001$ & 0.061 \\
\hline Blood lead & 0.163 & 0.086 & 0.058 & 0.002 \\
\hline Blood 1 & 0.185 & 0.076 & 0.015 & 0.241 \\
\hline \multicolumn{5}{|l|}{ Female $(n=1329)$ : } \\
\hline Age $^{\star}$ & 0.605 & 0.029 & $<0.001$ & 0.242 \\
\hline Body mass index & 1.544 & 0.134 & $<0.001$ & 0.091 \\
\hline Blood lead & 0.082 & 0.126 & 0.516 & 0.001 \\
\hline Blood lead $\dagger$ & -0.057 & 0.109 & 0.603 & 0.274 \\
\hline
\end{tabular}

*Univariate regression analyses with age, body mass index, or blood lead as independent variables, and blood pressure as dependent variable.

†After adjusting for potential confounders of age, age ${ }^{2}$, body mass index, milk intake, alcohol consumption, and cigarette smoking with model $\mathrm{R}^{2}$.

Table 4 Regression analysis of blood lead concentration and diastolic blood pressure before and after adjusting for potential confounders in different sexes

\begin{tabular}{lllll}
\hline $\begin{array}{l}\text { Independent } \\
\text { variables }\end{array}$ & $\begin{array}{l}\text { Regression } \\
\text { coefficient }(\beta)\end{array}$ & $\begin{array}{l}\text { Standard } \\
\text { error of } \beta\end{array}$ & $p$ Value & $R^{2}$ \\
\hline Male $(\mathrm{n}=1471):$ & & & & \\
$\quad$ Age & 0.171 & 0.018 & $<0.001$ & 0.059 \\
$\quad$ Body mass index & 0.824 & 0.084 & $<0.001$ & 0.061 \\
$\quad$ Blood lead & 0.079 & 0.056 & 0.157 & 0.001 \\
$\quad$ Blood lead $\dagger$ & 0.075 & 0.053 & 0.159 & 0.117 \\
Female (n=1329): & & & & \\
$\quad$ Age & 0.253 & 0.020 & $<0.001$ & 0.109 \\
$\quad$ Body mass index & 0.984 & 0.083 & $<0.001$ & 0.096 \\
Blood lead & -0.017 & 0.078 & 0.833 & 0.001 \\
$\quad$ Blood lead $\dagger$ & -0.083 & 0.072 & 0.250 & 0.171 \\
& & & &
\end{tabular}

*Univariate regression analyses with age, body mass index, or blood lead as independent variables and blood pressure as dependent variable.

†After adjusting for potential confounders of age, age $^{2}$, body mass index, milk intake, alcohol consumption and cigarette smoking with model $\mathrm{R}^{2}$.

importance for blood pressure. We used a backward elimination procedure to select the variables for the final model. The final model included those variables still significant at the $\mathrm{p}<0.05$ level and with biological relevance in predicting blood pressure. Variables that did not contribute to the model based on the selection criteria were eliminated and a final model was fitted. For the final model, the independent variables comprised continuous variables such as age, age ${ }^{2}, \mathrm{BMI}$, and $\mathrm{PbB}$, and categorical variables such as milk intake, alcohol consumption, cigarette smoking, $\mathrm{PbB}$, and systolic or diastolic blood pressure were the dependent variables. $\mathrm{Age}^{2}$ was included as a non-linear term.

The study subjects, stratified by sex, were divided into three subgroups by $\mathrm{PbB}:<10$, $10-20$, and $>20 \mu \mathrm{g} / \mathrm{dl}$, and the mean blood pressures were compared by analysis of variance (ANOVA) after adjustment for age, age ${ }^{2}$,

Table 5 Adjusted blood pressure ${ }^{\star}$ among different blood lead groups with sex stratification

\begin{tabular}{lccc}
\hline Blood lead & $<10 \mu g / d l$ & $10-20 \mu g / d l$ & $>20 \mu g / d l$ \\
\hline Male (n) & 1213 & 218 & 40 \\
SBP (mm Hg) & $126.1(16.9)$ & $129.1(18.7)$ & $129.1(17.1)$ \\
DBP (mm Hg) & $79.7(10.8)$ & $81.4(12.9)$ & $80.1(11.9)$ \\
Female (mm Hg) & $(\mathrm{n}=1206)$ & $(\mathrm{n}=105)$ & $(\mathrm{n}=18)$ \\
SBP (mm & $119.4(18.0)$ & $119.0(19.8)$ & $119.9(16.5)$ \\
DBP (mm Hg) & $75.5(11.3)$ & $74.4(11.3)$ & $74.6(10.6)$ \\
\hline
\end{tabular}

${ }^{\star}$ Mean (SD) adjusted for age, age ${ }^{2}$, body mass index, milk intake, alcohol consumption, and cigarette smoking.

$\mathrm{SBP}=$ systolic blood pressure; $\mathrm{DBP}=$ diastolic blood pressure.
BMI, milk intake, alcohol consumption, and cigarette smoking. ${ }^{15}$

\section{Results}

We sampled 2919 people in this survey. After excluding 119 subjects who had incomplete or missing data, the final sample for analysis was 2800 subjects (1471 males and 1329 females) with a mean (range) age of $44.3(15-85)$ years. The general characteristics of the study population are shown in table 1 . Among all study subjects, the mean systolic blood pressure was 123 and diastolic blood pressure $78 \mathrm{~mm} \mathrm{Hg}$, and the mean (range) $\mathrm{PbB}$ was 6.5 (0.1-69.1) $\mu \mathrm{g} / \mathrm{dl}$.

Table 2 shows the Pearson correlation coefficients between age, body weight, body height, $\mathrm{BMI}$, blood pressure, and $\mathrm{PbB}$ among males and females. In both sexes, age, body weight, and BMI were positively correlated with systolic and diastolic blood pressure. There was no significant correlation between age, body weight, $\mathrm{BMI}$ and $\mathrm{PbB}$ or the logarithmic transformed $\mathrm{PbB}$ among males or females. There was no significant correlation between blood pressure and $\mathrm{PbB}$ or the logarithmic transformed $\mathrm{PbB}$ in either sex.

Tables 3 and 4 present the sex specific multiple regression analyses to evaluate the association between $\mathrm{PbB}$ and blood pressure after adjustment for the potential confounders of age, age, ${ }^{2} \mathrm{BMI}$, milk intake, alcohol consumption, and cigarette smoking. The final model can explain about $25 \%$ and $15 \%$ of the total variance of systolic and diastolic blood pressure. Among males, the regression coefficients of $\mathrm{PbB}$ and systolic blood pressure were of borderline significance before and after adjustment for other potential confounders $(p=0.058$ and $\mathrm{p}=0.015$ respectively). The $\mathrm{PbB}$ was not significantly associated with diastolic blood pressure after adjustment for other potential confounders and did not seem to be a strong predictor for diastolic blood pressure in either sex. Among females, there was a trend for increasing systolic and diastolic blood pressure when $\mathrm{PbB}$ was lowered. Our results also showed that $\mathrm{PbB}$ was not as good a predictor of blood pressure as either age or BMI among this study population.

Table 5 shows sex stratified blood pressure (after adjustment for age, age ${ }^{2}$, BMI, milk intake, alcohol consumption, and cigarette smoking) among the subgroups with different $\mathrm{PbB}$. The subgroups with higher $\mathrm{PbB}$ did not show higher blood pressures than the subgroups with lower PbB. There was no significant difference in blood pressure among subjects with different concentrations of $\mathrm{PbB}$.

\section{Discussion}

In this study, we only found a borderline association between systolic blood pressure and $\mathrm{PbB}$ among males, and there was no significant association between diastolic blood pressure and $\mathrm{PbB}$ in either sex. Blood pressure did not change significantly between subgroups with different $\mathrm{PbB}$ and it seemed not to be a strong predictor of blood pressure; it was similar to some other studies in that there was 
only a small and weak association between $\mathrm{PbB}$ and blood pressure among the general population. ${ }^{34}$ Also, some epidemiological studies did not find consistent results for the association between $\mathrm{PbB}$ and blood pressure..$^{10-18}$

Several studies have, however, shown a positive association between $\mathrm{PbB}$ and blood pressure. Mechanisms suggested were the effect of lead on the calcium mediated control of vascular smooth muscle contraction and the renal effects mediated through the renin-angiotensin system. $^{2-4}$

Some studies have shown an inverse correlation between body lead concentration and milk intake ${ }^{19}$ and alcohol consumption was an effect modifier of the relation between $\mathrm{PbB}$ and blood pressure. ${ }^{20}$ In this study, we considered the dietary characteristics (especially milk intake) and alcohol consumption as potential confounders for the relation between $\mathrm{PbB}$ and blood pressure and adjusted for these.

The relative lack of correlation in our study may be because $\mathrm{PbB}$ only represents the transient, and not long term, body burden of lead. Perhaps only a marker of long term body lead accumulation-such as bone lead concentration-could give a good association between blood pressure and body lead concentration. ${ }^{16}{ }^{17}$ The limitations of cross sectional study may explain the lack of association between $\mathrm{PbB}$ and blood pressure.

A significantly association between $\mathrm{PbB}$ and systolic blood pressure among males (a decrease of $10 \mu \mathrm{g} / \mathrm{dl}$ in $\mathrm{PbB}$ was associated with a decrease of $1.9 \mathrm{~mm} \mathrm{Hg}$ in systolic blood pressure and 0.8 $\mathrm{mm} \mathrm{Hg}$ in diastolic blood pressure) was similar to the results of other studies. ${ }^{318}$ The lack of significant effects in females could be because there was only a small variation in $\mathrm{PbB}$ among the females in this population, which could have mitigated against finding any effects.

In summary, in this study, $\mathrm{PbB}$ seemed not to be a strong predictor of blood pressure, and there was only a weak association between $\mathrm{PbB}$ and systolic blood pressure. However, we can- not rule out a possible relation between long term body lead burden and high blood pressure. ${ }^{16-18}$

This study was supported by the Department of Health, Executive Yuan, Taiwan, ROC. We acknowledge Drs Richard Monson, Marcia Testa, and Howard $\mathrm{Hu}$ for their comments and valuable guidance on early version of the manuscript.

1 Goyer RA. Lead toxicity: crent concerns. Environ Health Perspect 1993;100:177-87.

2 Preuss HG. A review of persistent, low-grade lead challenge: neurological and cardiovascular consequences. $\mathcal{f} \mathrm{Am}$ Coll nutr 1993;12:246-54

3 Schwartz J. Lead, blood pressure, and cardiovascular disease in men. Arch Environ Health 1995;50:31-7.

4 Pirkle JL, Schwartz J, Landis JR, et al. The relationship between blood lead levels and blood pressure and its cardiovascular risk implications. Am $\mathcal{F}$ Epidemiol 1985;121: 246-85

5 Fanning D. A mortality study of lead workers, 1926-85. Arch Environ Health 1988;43:247-51.

6 Cooper WC, Gaffey WR. Mortality of lead workers. F Occup Med 1975;17:100-7.

7 Michaels D, Zoloth SR, Srtern FB. Does low-level lead exposure increases risk of death? A mortality study of newspaper printers. Int $\mathcal{F}$ Epidemiol 1991;20:978-83.

8 Steenland K, Selevan S, Landrigan P. The mortality of lead smelter workers: an update. Am $\mathcal{F}$ Public Health 1992;82: smelter

9 Selevan SG, Landrigan PJ, Stern FB, et al. Mortality of lead smelter workers. Am f Epidemiol 1985;122:673-83.

10 Moller L, Kristensen TS. Blood lead as a cardiovascular risk factor. Am F Epidemiol 1992;136:1091-100.

11 Liou SH, Wu TN, Chiang HC, et al. Blood lead levels in the general population of Taiwan, Republic of China. Int Arch Occup Environ Health 1994;66:255-60.

$12 \mathrm{Chu}$ NF, Lee MS, Wang DJ, et al. The reappraisal of the association of glycosylated hemoglobin A1c (HbA1c) and
blood pressure: a hypertension and diabetes study in Taiwan rural area. f Clin Epidemiol 1993;46:173-9.

13 Liou SH, Yang GY, Wu TN, et al. Assessment of interlaboratory performance on the measurement of blood lead levratory performance on the measurement of blood lead

14 Hammad TA, Sexton M, Langenberg P. Relationship between blood lead and dietary iron intake in preschool children. Ann Epidemiol 1996;6:30-3.

15 Selvin S. Statistic analysis of epidemiologic data, 2nd ed. New York: Oxford University Press; 1996.

16 Wu TN, Shen CY, Ko KN, et al. Occupational lead exposure and blood pressure. Int F Epidemiol 1996;25:791-6.

$17 \mathrm{Hu} \mathrm{H}$, Aro A, Payton M, et al. The relationship of bone and blood lead to hypertension. The normative aging study. ҒAMA 1996:275:1171-6.

18 Staessen JA, Roels H, Lauwerys RR, et al. Low-level lead exposure and blood pressure. F Hum Hypertens 1995;9: 303-28.

19 Hernandez-Avila M, Gonzalez-Cossio T, Palazuelos E, et al. Dietary and environmental determinants of blood and bone lead levels in lactating post-partum women living in bone lead levels in lactating post-partum women living in

20 Hense HW, Filipiak B, Keil U. Alcohol consumption as a modifier of the relation between blood lead and blood pressure. Epidemiology 1994;5:120-3. 